\title{
Interpretation of the results of monitoring of the displacement of the Tresna dam in 2016
}

\author{
Stanisław Lach, ${ }^{*}$ \\ AGH University of Science and Technology, Faculty of Mining Surveying and Environmental \\ Engineering, Department of Environmental Management and Protection, 30 Mickiewicza Av., 30-059 \\ Krakow, Poland.
}

\begin{abstract}
Impounding structures are exposed to complex loads. Utilized in various conditions, they are subjected to different kinds of studies and longterm displacement surveys, as they could be exposed to the disturbance of stability principles. Building structures must be verified for safety not only at the operational stage, but at the design stage as well. Therefore, prototype tests are carried out to avoid construction failures and their consequences in the future [1]. The aim of the paper is to assess the technical conditions and level of safety of the Tresna dam located on the Żywiecki Reservoir based on the results of monitoring of the displacement in 2016. The obtained results were confronted with data on displacements from the period 20052015. The scope of the research concerns mainly the issue of displacements monitored in the shell of the dam, the bottom outlet, the building of the hydroelectric power plant, the intake tower and the retaining wall. In addition to the measurements carried out at the dam also displacements on the area of the landslide near the building were monitored.
\end{abstract}

\section{Introduction}

The term "monitoring" translates into a short-term or long-term organized observation method [2]. Hydraulic structures, especially dams, may pose a serious threat to the environment, because the rupture of this type of a facility may bring on tragic consequences $[3,4]$. The safety of a structure is determined by various factors, including, among others: endogenous (tectonic) movements, exogenous movements, the aging process of materials and the occurrence of construction errors, assembly errors and, in extreme cases, also destructive actions, e.g. terrorism or war. Monitoring of hydraulic structures is based on the control of measuring devices which these structures are equipped with $[5,6]$. They allow for continuous verification of the technical condition of a structure, both during the construction stage and in the course of its operation. The type and number of installed devices are determined by the class of a structure, its design and the type of the base surface [7]. Monitoring covers mainly: surveys of horizontal and relative displacements, surveys of subsidence, deflections, etc. The structures classified as class III and class IV are subjected to selected types of tests, usually piezometric measurements and surveying subsidence tests.

\footnotetext{
*Corresponding author: slach@agh.edu.pl
} 
automated devices are also used [8].

Modern hydraulic structures are equipped with Automatic Systems of Technical Dam Control (ASTDC), which are individually designed for each facility. This type of a monitoring tool includes sensors, associated meters, relays and a computer that allows for the collection and analysis of the collected data [2]. Today, modern hydraulic structures are equipped with automatic measuring systems that make it possible to control their safety on an ongoing basis, already at the construction stage [9]. Although Automatic Systems of Technical Dam Control allow for a very accurate analysis of the safety of hydraulic structures, their potential is not fully utilized yet.

\section{Material and methods}

The Tresna reservoir is located in the province of Silesia. It was created by the earth and rock-filled dam constructed on the Soła river at $40+025 \mathrm{~km}$ from its source, in the village of Tresna. At the maximum impounding level, it covers an area of $9.64 \mathrm{~km}^{2}$, while its total capacity amounts to $96.11 \cdot 10^{6} \mathrm{~m}^{3}$. The accumulation of water in the reservoir is used in the hydroelectric power station located on the left bank of the Sola river. It is a free-standing structure, partially cutting into the bottom of the embankment, independent of its structure. This peaking and storage power plant generates power equal to $21 \mathrm{MW}$ and produces an average of $28.40 \mathrm{GWh}$ of electricity annually. The Tresna reservoir has increased the touristic values of the region and has created favorable conditions for the construction of recreation centers in this attractive piedmont area. The earth and rock-filled dam in Tresna closes the catchment of an area of $1030 \mathrm{~km}^{2}$. It impounds water to the elevation of $342.70 \mathrm{~m}$ above mean sea level.

The static embankment dam in Tresna was constructed of local materials - gravels (Gr) and pebbles (Co). The upstream slope is armored with $12 \mathrm{~cm}$ thick reinforced concrete slabs. The slabs have $20 \mathrm{~cm}$ drainage holes, spaced every $2.5 \mathrm{~m}$. Additional filter layers composed of the material with grains with a diameter of over $20 \mathrm{~mm}$ are also laid on three levels in the static embankment. This is to facilitate the outflow of water from the shell of the dam. From the side of the bottom water level, directly on the embankment, an intermediate layer is laid with a vertical thickness of $3.0 \mathrm{~m}$. There is a rock riprap on it, which consists of two parts: the main rock armor (made of rock blocks weighing $>50 \mathrm{~kg}$ ) and the facing layer (made of blocks weighing $>150 \mathrm{~kg}$ ). The deformations and displacements of the dam in Tresna are controlled by 111 benchmarks, including: on the shell of the dam - 15 benchmarks, on the bottom outlet - 18 benchmarks, on the spillway (on the left side - 21 benchmarks, on the right side - 27 benchmarks), on the bridge over the spillway - 9 benchmarks, on the inlet to the tunnel - 4 benchmarks, on the hydroelectric power plant - 9 benchmarks, on the retaining wall - 8 benchmarks [11].

\section{Results and discussion}

The results, which form the basis for this research paper, have been made available by the Regional Water Management in Krakow. These include a collection of data on displacements which occurred in 2016. Geodetic field surveys were performed on 5-9 September 2016 at the average air temperature $\mathrm{t}=23^{\circ} \mathrm{C}$ and the average impounding upper water level $=339.97$ $\mathrm{m}$ AMSL. Before the surveys, a technical inspection of the monitored benchmarks and reference benchmarks had been carried out, with the exception of the reference benchmarks 1010 and 1011, which had been destroyed during the reconstruction of the restaurant, and the monitored benchmark 217, which had been damaged during the construction of the crane. 
Other benchmarks were found to be in good technical condition. At the same time as the surveys were being carried out on the dam, displacements were also determined in the landslide located near the hydraulic structure. The landslide monitoring network consisted of four measurement cross-sections. During the inspection, it was found that:

- benchmark 3 was impossible to be surveyed due to its location in a closed area,

- benchmark 152 on the side of the road had been destroyed.

Research studies on the dam deformation have been carried out since 1965. A leveling network has been designed for this structure (Fig. 1, Fig. 2), representing the distribution of individual benchmarks.

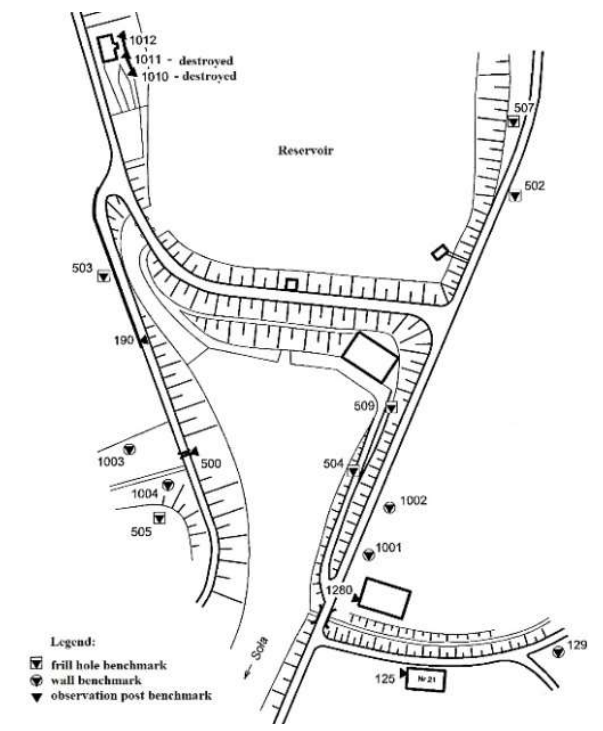

Fig. 1. Sketch of distribution of reference benchmarks for Tresna dam [11]. 


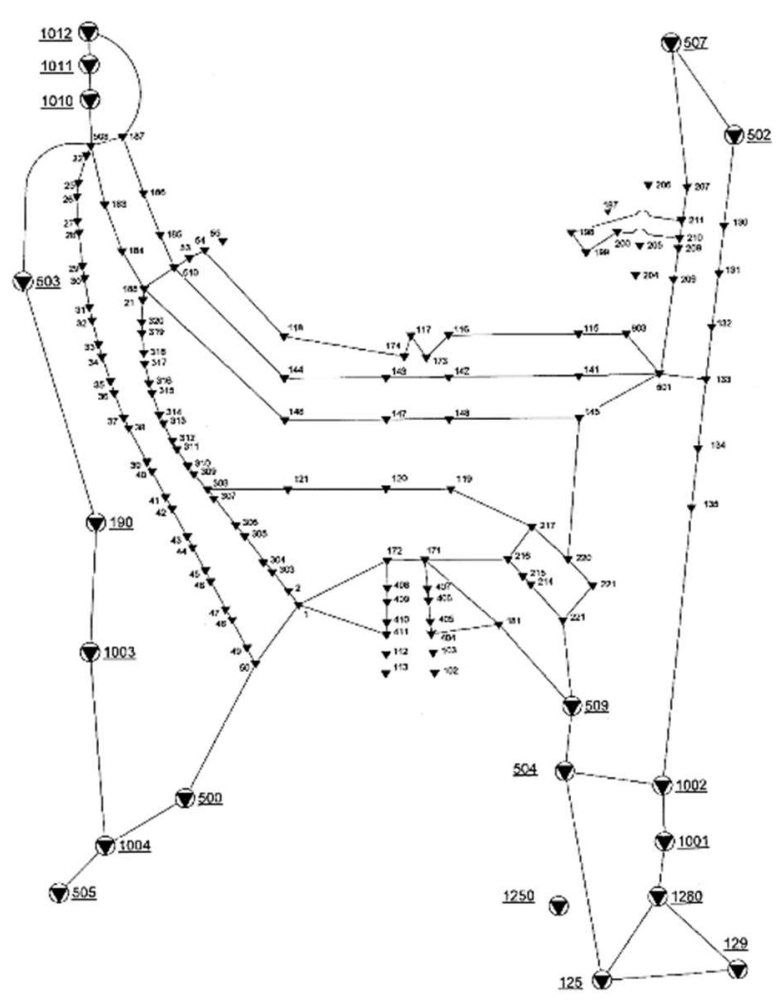

Fig. 2. Sketch of leveling network of Tresna dam [11].

\subsection{Total vertical displacements of the dam}

Several elevation points, serving as reference benchmarks, were placed on buildings located in the vicinity of the dam. The data obtained from the surveys of benchmark displacements, which have been determined since 1984, were analyzed for their invariability. Mutual invariability of the following benchmarks was observed: 125, 129, 502, 505, 507, 1001, 1002 , 1003 and 1004. Mean errors of vertical displacements of the above-mentioned points fell within the interval: $\mathrm{m}_{\Delta}= \pm(0.2-0.6) \mathrm{mm}$. It may be assumed that the fixed elevation points and their slight displacements are related to the movements of the layers of the earth's crust. Other benchmarks, exhibiting a variable mutual position, are subject not only to age displacements but also to local ones. The reference points are aimed at direct or indirect monumentation of all local systems, from the moment of performing the initial measurement until the end of the research studies performed on the structure [12].

\subsection{Vertical displacements on the shell of the analyzed dam}

Throughout the entire lifespan of the dam, since it was constructed in 1965, the occurrence of vertical displacements have been observed. There are a few gaps in the set of the obtained measurement data, though. First of all, it is due to the fact that at the turn of 1991/1992, the last emptying of the reservoir took place, resulting in a break in measurements of displacements of all analyzed benchmarks located on the shell of the dam. As many as four of the fifteen analyzed benchmarks placed on its shell of dam were not subjected to annual surveys. Due to their unavailability in 2005 and 2006, the benchmarks 118, 117, 146, 115 
caused further gaps in the survey results, breaking the continuity in the obtained data set (Fig. 3, Fig. 4). The smallest subsidence increments, compared to 2015 , were recorded for the benchmark $119(0.0 \mathrm{~mm})$ and for the benchmark $142(0.0 \mathrm{~mm})$. The largest ones were noted for the benchmark $116(0.8 \mathrm{~mm})$. Due to the values of displacements of specific elevation points, there are no grounds to talk about their negative influence on the safety of the dam. A significant factor favoring the occurrence of subsidence is most probably the load on the structure related to water impounding and, to a large extent, the ambient temperature.

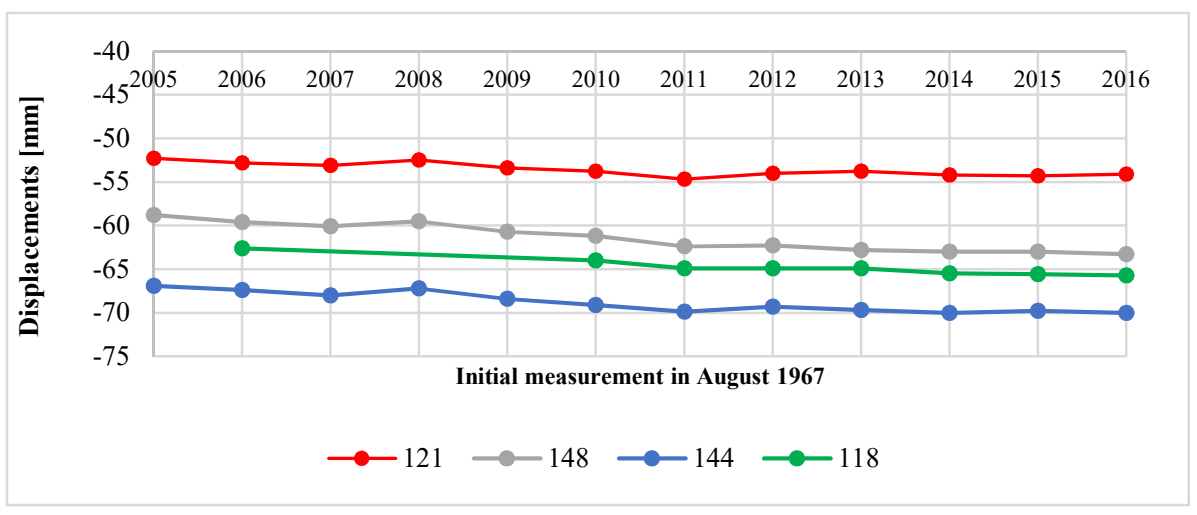

Fig. 3. Total vertical displacements of frontal dam in Tresna.

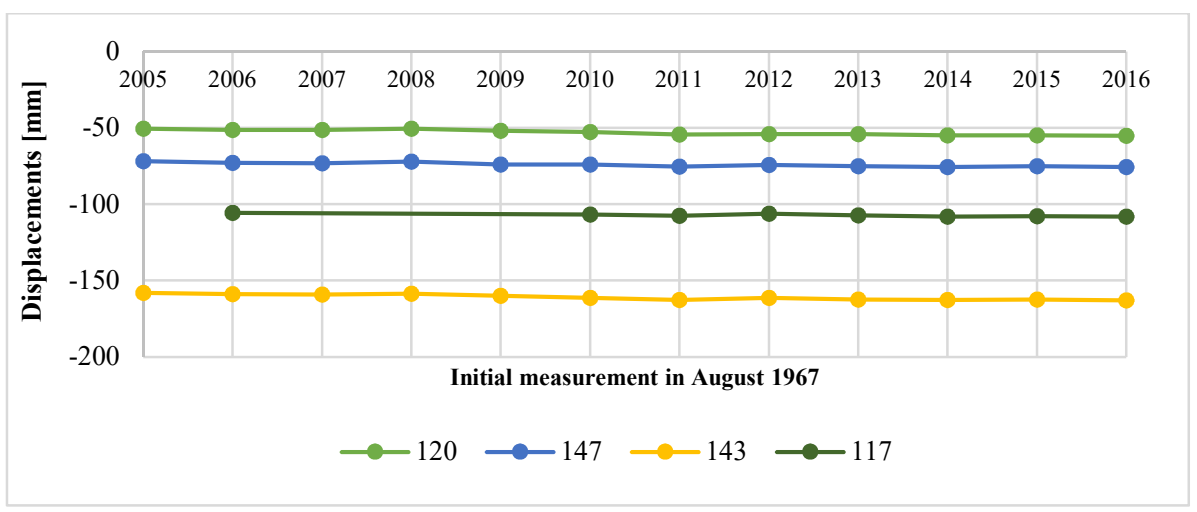

Fig. 4. Total vertical displacements of frontal dam in Tresna, follow-up.

\subsection{Vertical displacements of the bottom outlet}

The analysis of subsidence of the benchmarks located within the bottom outlet, similarly to the ones located on the shell of the dam, exhibited minimal displacements (Fig. 5, Fig. 6). The benchmarks 173 and 174, placed above the lock chamber, were unavailable in 2005 and 2009. Despite this gap in the measurement data, no displacements, which would be exceptionally large when compared to others, occurred in 2010. It can be concluded that within these two years, the structure with the lock chamber was subject to a slight, but progressing, subsidence. The benchmarks 171 and 172, located at the spillway of the bottom outlet, also exhibited minimal movements. Since the dam was constructed, the surveys were performed each year, and the total subsidence of the benchmarks, which results from continuous measurements since 1966, has been $-3.4 \mathrm{~mm}$ for the benchmark 171, and $-3.2 \mathrm{~mm}$ for the benchmark 172. The elevation points 404-411 were again monumented in 2009. The smallest subsidence increments, compared to 2015, were recorded for the benchmark 405 
$(0.0 \mathrm{~mm})$. The largest values of $+0.1 \mathrm{~mm}$ were noted for the benchmarks $404,410,411$ and for $409-0.3 \mathrm{~mm}$.

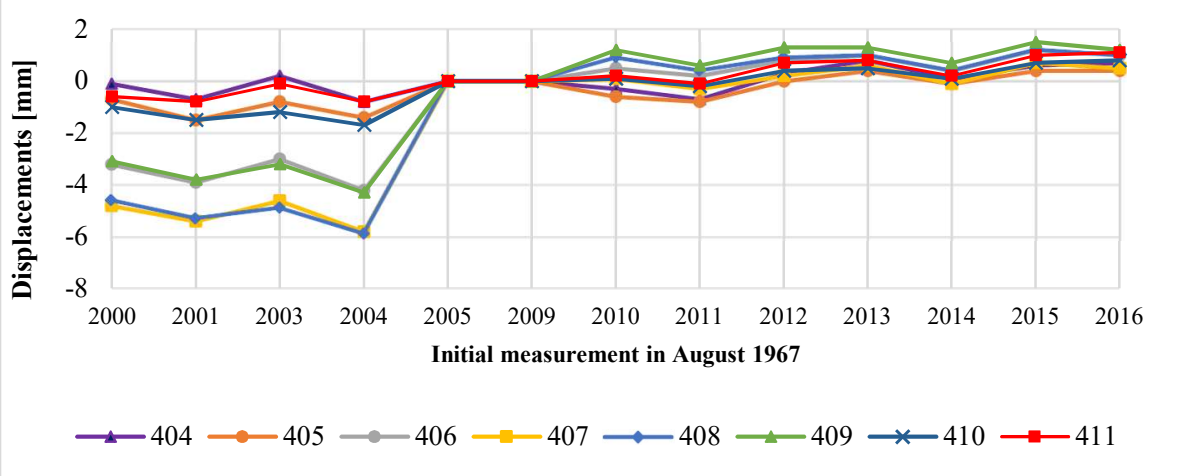

Fig. 5. Total vertical displacement of bottom outlet of Tresna dam.

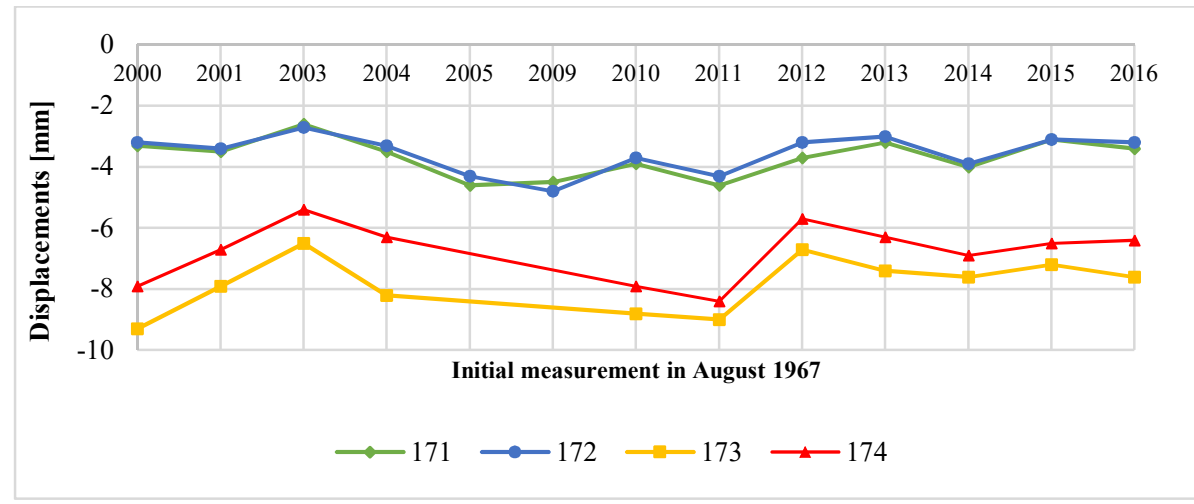

Fig. 6. Total vertical displacement of bottom outlet of Tresna dam, follow-up.

\subsection{Vertical displacements of the building of the hydroelectric power plant}

Based on the displacement results obtained from the power plant building, it was easy to observe a large scatter in the total subsidence values (Fig. 7, Fig. 8). The maximum value of displacement $(-26.1 \mathrm{~mm})$ was noted for the benchmark 216 , while the minimum subsidence of $-0.3 \mathrm{~mm}$, i.e. the difference of several dozen $\mathrm{mm}$, was exhibited by the benchmark 222 . The noticeable difference is large, however, the values of the obtained results are small enough, so that there are no grounds to consider these displacements as a threat to the safety of the analyzed structure. Three of the available benchmarks located on the power plant building were destroyed. As it can be seen in Figure 4.6, the interpretation of progressing displacements is hindered, which makes it difficult to predict and prevent possible adverse effects of subsidence that may appear in the future. First of all, it is necessary to restore the benchmark 217, which exhibited the highest subsidence value (in 2014, displacements of $28.2 \mathrm{~mm}$ were recorded). In 2016, the benchmarks on the power plant building exhibited subsidence of $-0.3 \mathrm{~mm}$ and elevation of up to $+0.1 \mathrm{~mm}$. 


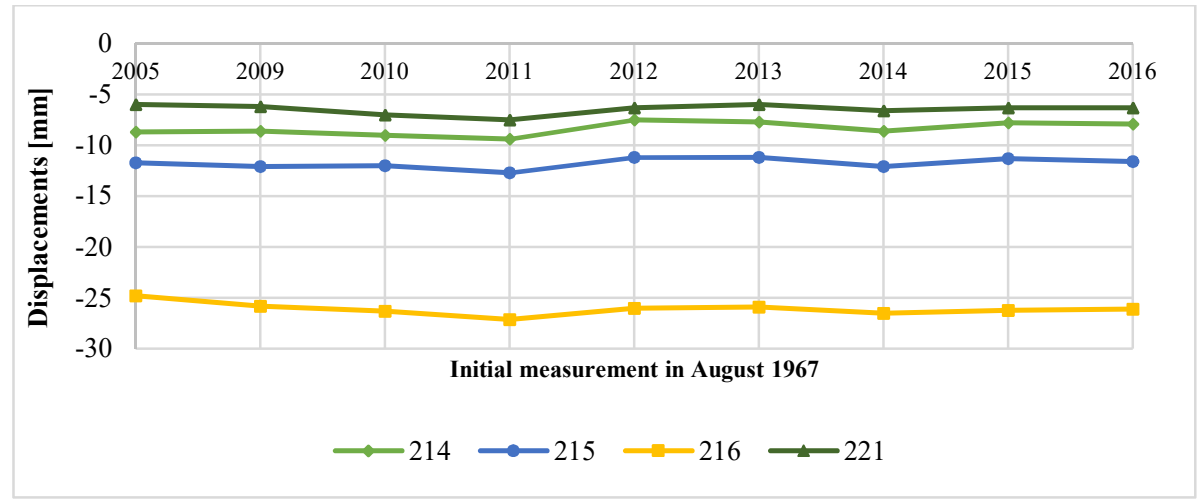

Fig. 7. Total vertical displacement of Tresna power plant.

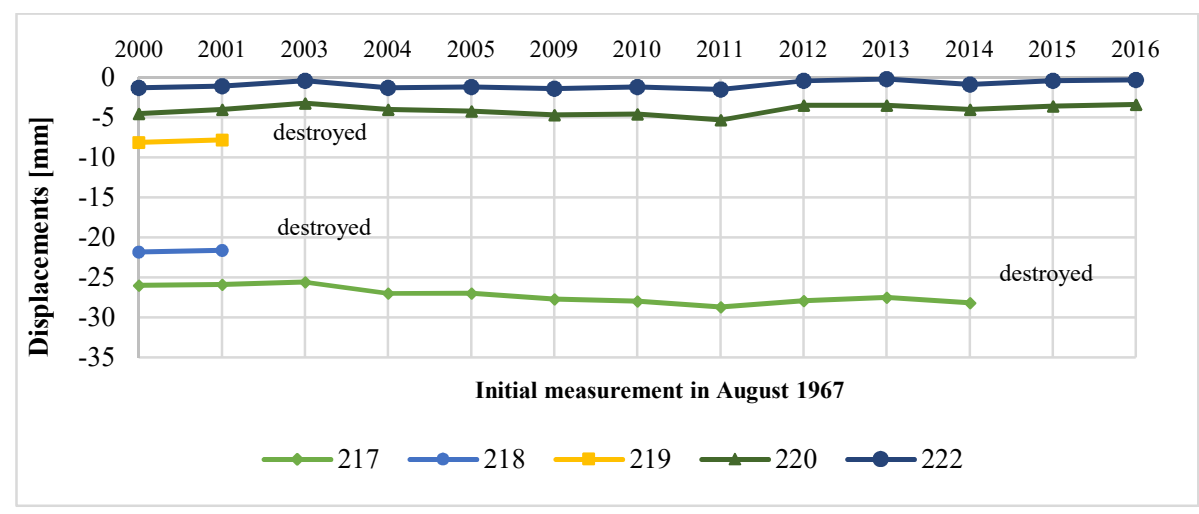

Fig. 8. Total vertical displacement of Tresna power plant, follow-up.

\subsection{Vertical displacements of the intake tower and the retaining wall}

Four benchmarks were placed on the intake tower: 197, 198, 199, 200 (Fig. 9). They have been used in surveys since the dam was constructed (except in 1992, when the reservoir was emptied, which resulted in a data gap). In the years 2006-2010, the lack of measurement results for the benchmark 197 can be observed, which resulted from the destruction of this elevation point. Regardless of all the data gaps, when analyzing total subsidence of the structure over the years, slight displacements have been noted (from $-1.6 \mathrm{~mm}$ to $-2.6 \mathrm{~mm}$ ). This is undoubtedly a proof of stable conditions for the foundation of the intake tower. On the other hand, taking into account displacements which occurred only in the previous year (2006), subsidence values were observed from $-1.1 \mathrm{~mm}$ (benchmark 200) to $-1.5 \mathrm{~mm}$ (benchmark 197).

The benchmarks located on the retaining wall have been used in surveys since 1965 (Fig. 10). The elevation points 204, 205, 206 stand out from the others with a clear discontinuity of the data. Moreover, the benchmark 206 was destroyed in 2010, and has not been used in surveys ever since. In 2006, there were displacements of benchmarks ranging from -1.0 mm (benchmark 209) to $+0.4 \mathrm{~mm}$ (benchmark 205). The largest subsidence of the retaining wall could be observed in the first years after the erection of the structure. Their increments were decreased and adjusted over time. While analyzing the total subsidence, the displacements which were recorded ranged from $-11.8 \mathrm{~mm}$ (benchmark 205) to $-38.5 \mathrm{~mm}$ (benchmark 208). 


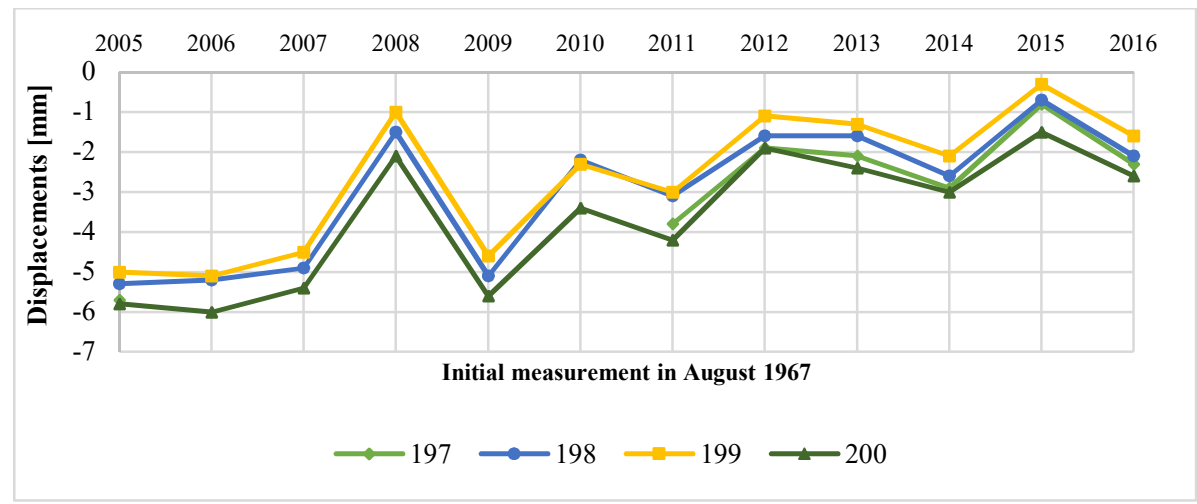

Fig. 9. Total vertical displacement of intake tower of Tresna dam.

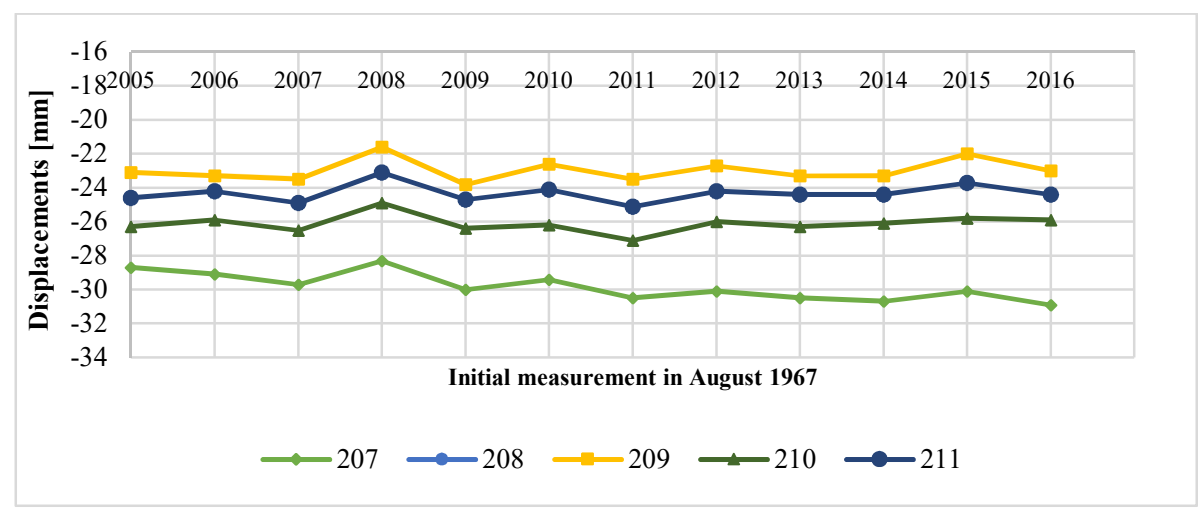

Fig. 10. Total vertical displacement of retaining wall of Tresna dam.

\subsection{Displacement of landslide No. 3}

In the analysis of displacements occurring in the landslide No. 3, the results were compared with the data obtained during the initial measurement carried out in November 1986. Four cross-sections were marked within this landslide (Fig. 11), where displacement surveys were performed. After the analysis of invariability of reference benchmarks from the network of elevation points used for determining vertical displacements, the benchmarks 110, 111, 112, 1005, 1007 and 1008 were removed. Thus, mutual invariability of the following elevation points was observed: 204, 1004, 1006 and 1009. Vertical displacements are burdened with mean errors, the values of which do not exceed $m_{\Delta}= \pm 0.5 \mathrm{~mm}$. In the case of horizontal displacements, the stability of elevation points has been predetermined without an analysis. The point displacement survey has been burdened with a mean error of the following values:

- from $m_{\Delta}= \pm 2.0 \mathrm{~mm}$ (for points located within $100 \mathrm{~m}$ from the observation stand),

- up to $m_{\Delta}= \pm 4.0 \mathrm{~mm}$ (for control points located more than $150 \mathrm{~m}$ from the observation stand). 


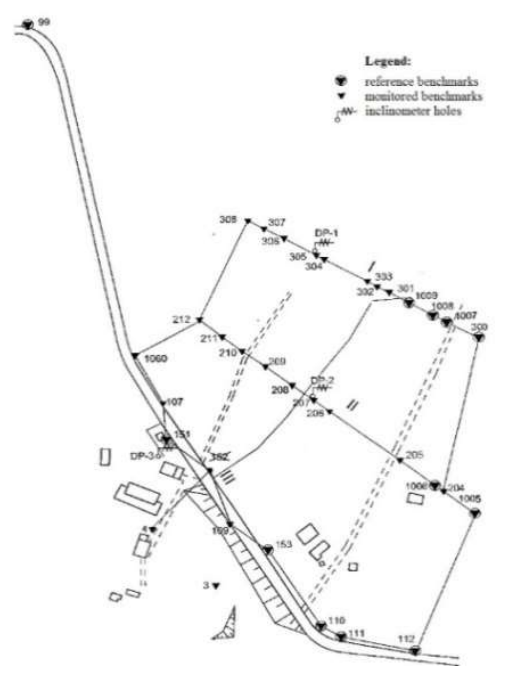

Fig. 11. Sketch of benchmark network for determining vertical displacements for landslide No. 3 [11].

In the area of the I-I cross-section (upper one), measurements of subsidence increments for most benchmarks were commenced in 1983. The elevation point 300 was the only one for which the year 1986 was adopted as the reference year for the estimation of displacements. Since 1983, no damage was noted to any of the elevation points, nor any circumstances occurred throughout the entire period when subsidence increments were being determined that could affect the surveying procedure. The measurement data demonstrates that each of the benchmarks has a complete set of recorded values. The only missing information that could result in difficulties in interpretation of the displacements are the gaps in the recorded measurement years (before 2005). For example, in the period from September 1993 to September 1999, there is a large scatter in the values of the surveyed displacements. These significant discrepancies occur for the benchmarks 308-301 and range from -26.0 mm (benchmark 308) to $-41.0 \mathrm{~mm}$ (benchmark 306). It can be assumed, however, that in this period the displacements of the landslide No. 3 were evenly distributed, which cannot be seen exactly due to the lack of data in this time interval. It has been found that benchmarks 308301 have a general tendency to subside. In the period from November 2015 to November 2016, which is the most important in the interpretation for this research paper, the largest increments in displacements which were recorded during these two years were $+4.0 \mathrm{~mm}$ (for benchmarks 302, 301, 300).

The middle cross-section II-II of the landslide No. 3 covers the network of benchmarks 212-1005. The displacement surveys were carried out at the same values of temperature and upper water levels, as for the cross-section I-I. The displacement surveys did not start at the same time for all the elevation points included in the network. Some of them (as in the case of the cross-section I-I) began to be monitored as late as in 1986. Since the first measurements of displacements in the landslide No. 3, a tendency to slow, but permanent subsidence of the ground could be observed. In the last period (November 2015-November 2016), the maximum displacements observed in the analyzed area did not exceed $-4.0 \mathrm{~mm}$. Two of the benchmarks (1005 and 1006), did not exhibit any displacement.

The displacements measured for particular benchmarks within the cross-section III-III (bottom one, along the road) were distributed very unevenly. First of all, it is due to the fact that not all elevation points were measured at the same time (benchmarks 1060, 151, 152, 153 were monumented later than the others). In addition, there are a lot of gaps in the 
to the lack of data since 2006, points 99 and 100 have been useless in the general analysis of displacement distribution. Similarly, benchmark 152 was destroyed in 2012 and has never been restored. The remaining benchmarks exhibit the subsidence values at the levels from $8.0 \mathrm{~mm}$ (benchmark 109) to $-11.0 \mathrm{~mm}$ (benchmarks 151 and 153).

The cross section IV-IV covers the benchmarks located under the road. The elevation points 2, 1003, 1002, 1001, 1, were destroyed in 2005 and no attempt was made to have them restored. In the control network of the cross-section IV-IV, there are two benchmarks (4 and 3 ), but distribution of their displacements is possible to be analyzed only for the control No. 4. In the period from November 2015 to November 2016, this benchmark has displaced by $10.0 \mathrm{~mm}$.

\section{Conclusions}

The largest displacements of the benchmarks for the analyzed dam occurred after the flood in 1997 (10.0 mm on average). Although the previous results of measurements obtained from individual cross-sections did not exhibit significant displacements, it should be remembered that there is a potential threat in the landslide No. 3. Displacements, even the smallest ones, carry the risk of a landslip. Within the landslide No. 3, in its central part, there are wetlands. Due to their nature and role they play (to irrigate the slope), the risk of a slip is even more serious. It is recommended to continuously maintain the irrigation ditches located within the landslide. Specially trained employees are obliged to carry out modernization and renovation works, as required by regularly conducted inspections.

One of the recommended possibilities to supplement the network of reference points is to analyze the calculated displacements per unit height of the dam. The level of the upper water table is essential in this matter, because differences in the values of displacements of individual neighboring points indicate the occurrence of stresses in the structure. In the places where the stresses are greatest, untightness of the building material may occur [13].

The design and material used have the greatest influence on slight displacements of impounding structures. The Tresna dam is the earth-filled structure. Because of the material which was used for its construction, there are some risks associated with the mixing of safety factors, which could lead to the loss of stability in the future. The performed geodetic surveys, however, unambiguously prove that the structure has a stable foundation and there is no risk for the loss of its stability. It is expected that further operation of the structure in the near future should proceed without any problems.

Restoration of the damaged benchmarks, which were revealed during the performance of the displacement surveys, is an important issue as well. The reference points 1010 and 1011 as well as the monitored benchmark 217 located on the power plant building are important for the accurate monitoring of displacements of the dam. In the landslide No. 3, the benchmark 152 located along the road appears to be very important, as well as other benchmarks requiring protection and located in this cross-section.

The paper has been prepared within the scope of the AGH UST statutory research no. 11.11.150.008.

\section{References}

1. Bakhaeva S., Guriev D. Proceedings of the 8th Russian-Chinese Symposium on Coal in the 21st Century - Mining, Processing, Safety, 92, 188 (2016)

2. Kledyński Z. Mod. Build. Eng. 2, 54 (2011)

3. Lach S. Jou. Wat. La. Dev. 33, 89 (2017)

4. Shao C., Gu C., Yang M., Xu Y., Su H. Str. Con. Hea. Mon. 25, 1 (2018) 
5. Lach S. Research and development of young scientists in Poland: Engineering Sciences and engineering, 5, 89 (2017)

6. Lach S. Jou. Eco. Eng. 19, 150 (2018)

7. Lazzarini T. Surveying measurements of displacement of the buildings and their surroundings (PCPC, Warsaw, 1977)

8. Regulation of the Minister of Environment of 20 April 2007 on the technical conditions, which should correspond to the hydro structures and their location (Polish Journal of Laws of 2007, No. 86, item 579)

9. Jankowski W. General guidelines for the control of weirs and dams construction (IMWM, Warsaw, 2008)

10. Godlewski B. Cascade on the Soła River. Reservoirs Tresna, Porabka, Czaniec (IMWM, Warsaw, 2007)

11. Materials of the Tresna Hydroelectric Power Station

12. Bednarczyk S., Bolt A., Mackiewicz S. The stability and safety of weirs and dams (Publishing House Of The Gdansk University Of Technology, Gdansk, 2009)

13. Peplińska-Zaczek J., Popielski P. Tech. Tran. 105, 211 (2008) 